In a letter in Nature of March 17 Prof. Herdman mentions that "the plaice in the open-air ponds at the Port Erin Biological Station started spawning on March 3, and those at the Piel (Lancashire) Sea Fish Hatchery (under cover) on March I." He would like to know how this record compares with that of fish in the sea. As the professor. suggests that " probably the officials of the International Investigation will be able to speak as to the condition in the North Sea and . . English Channel," I herewith state my experience.

About the middle of February I was informed by fishermen that plaice in the North Sea (southern part) were for the most part spent. From personal observation I can state that the larger plaice trawled by the s.s. Huxley in the Great West Bay on February 26 were spent. Further, the eggs procured in the tow-nets at the various hydrographic stations in the English Channel in the latter part of February can hardly fail to prove, on examination, to be those of plaice. Prof. Herdnan is probably aware that investigations conducted by the Marine Biological Association in the south Devon bays during 1901 and 1902 established the conclusion that "the maximum spawning period lies between the third week of January and the second week of February."

In regard to the North Sea, I may mention that I examined on board about 300 plaice trawled by the s.s. Huxley on Mareh II and I2 on the south-ivest part of the Dogger Bank, and that of these fish the larger were spent, the smaller immature. Only one female had a considerable remnant of ripe eggs in its ovary, but none of the males were " running." The eggs procured in the tow-nets in the southern part of the North Sea are apparently of several species, but plaice are almost certainly present, and probably predominate. From present facts and previous records I conclude that, as compared with the North Sea and English Channel, Prof. Herdman's plaice are late in starting to spawn.

Marine Laboratory, Lowestoft, March 20.

\section{Euclid's Definition of a Straight Line.}

ON p. 409 your reviewer states that " Euclid says nothing about the extreme points of the line "in his definition of a straight line, but regards " all the points on it."

Will he kindly look at p. 4 ro of your vol. ivii., where I have given reason for considering the older translation of Euclid's words to be correct.

R. E. B.

I HAVE read the passage referred to, but for many reasons cannot admit that the argument is conclusive. In the first place, the quotation from Aristotle's "Ethics" has no authority whatever; it has no grammatical connection with the previous context, and shows every mark of being a marginal annotation which has been wrongly incorporated with the text. Then the use of the same symbol for different points (AA, BB, $\Gamma$ r denoting segments) is very unusual. and is not what we should expect from a competent mathematician, so it is rash to infer that the use of 'é' $\hat{\omega} \nu \Gamma \Delta$ in the sense "of which $\Gamma, \Delta$ are the extremities " was a current technical practice at the time of the writer. But even if this be admitted, it does not follow that Euclid means the same thing in his definition of a straight line; all the evidence, it seems to me, points in another direction. Euclid has just defined points, and stated that the extremities of lines are points; if he had intended' what the current English translation makes. him say, would he not have written, "A straight line is a line which lies evenly ( $\dot{\xi} \xi$ ' $\sigma o v)$ with respect to its extremities"? Again, in i. 9 he says, "on $\mathrm{AB}$ let any point $\mathrm{D}$ be taken" ( $\epsilon i \lambda \hat{\eta} \phi \theta \omega \dot{\epsilon} \pi \dot{\imath} \tau \hat{\eta} s \mathrm{AB} \tau v \chi \dot{\partial} \nu$ $\sigma \eta \mu \in \hat{i} 0 \nu \tau \partial \Delta$ ); now if $\mathrm{D}$ is taken "on " $\mathrm{AB}$, surely it is included in "the points on $\mathrm{AB}$ " $(\tau \dot{\alpha}$ eे $\pi \imath \tau \hat{\eta} s \mathrm{AB} \sigma \eta \mu \epsilon \hat{\imath} \alpha)$. Moreover, Euclid explicitly recognises infinite, or indefinitely long, straight lines; the enunciation of $i$. $\mathrm{I}_{2}$ is

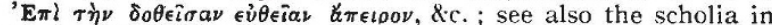
Heiberg's edition of the "Elements," v. $78-83$, 136-9.

The real difficulty, I think, is in the interpretation of $\dot{\boldsymbol{\epsilon}} \boldsymbol{\xi}$ Toov; what this is intended to mean can hardly be settled, unless new documents should be discovered. Personally, I believe that what Euclid had in his mind was something of this sort:-if we stand at any point $A$ on a straight line and look towards any other point B on it, the appearance of $A B$ is always the same, and the same as that which we get by going to $B$ and looking towards $A$. But this is only a conjecture; my principal contention is that $\tau \grave{\alpha} \dot{\epsilon} \pi l$

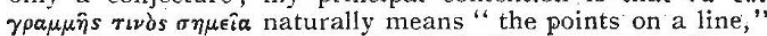
namely, all the points on it, including its extremity or extremities if it does not extend indefinitely both ways, and that this is the sense which the phrase bears in Euclid's definition of a straight line.

YOUR REVIEWER.

\section{Respiration in Frogs.}

THE respiratory, movements of frogs have been studied by several observers, especially Gaupp and Baglioni, of recent years. These zoologists have pointed out that the rapid up and down movement of the floor of the mouth, so typical of most batrachians, is a kind of aspiration, and does not force air in or out of the lungs to any great extent.

In a frog recently under observation I noticed these movements taking place while the creature was entirely submerged, and not engaged in croaking. I should be glad to learn whether this is an occurrence well known to your readers. To the best of my knowledge neither of the abovementioned naturalists allude to it, but I have not here access to their original papers (Gaupp, Archiv. für Anat. und Physiol., Anat. Abtheil, I896; Baglioni, ibid., Physiol. Abtheil, 1900).

Is it not possible that in certain circumstances, supposing the nostrils to be open and the glottis closed, even the adult frog may take in water into its mouth for the purpose of breathing? The remarkable condition of the blood capillaries in the mouth points to it as being normally a place for interchange of gases when air is admitted. If this suggestion be possible, the power possessed by frogs of undergoing prolonged immersion may be partially explained.

M. D. Hili

Zoological Laboratory, Eton College, Windsor, March 20.

\section{Subjective Colours.}

In the discussion on this subject in Nature I have not seen any mention of a phenomenon which $I$ have now and then noticed of late years, but never before, nor have I seen it described anywhere. When I have been reading and have become sleepy, just as I was about to fall asleep portions of the print in patches in different parts of the page turned a brilliant red. It is impossible to make any exact observations on the subject, because the moment one rouses oneself to do that the printing resumes its ordinary black. I do not find that this phenomenon is affected by the amount of light in any way.

The phenomenon mentioned by Mr. E. Hubbard (p. 318) is true in my case, and I attribute it to the fact that the eye that is exposed to the greatest light is more or less dazzled, or else has light reflected into it from the evelids, and so the field of view is suffused with red or orange light which combines with the tint seen with the shaded eye.

$$
\text { T. W. BACKHOUSE }
$$

West Hendon House, Sunderland, March 18.

\section{Secondary Radiations of Radium.}

I Exclose two prints I have taken with a radium screen. No. I shows the impression of a steel pen-nib, a steel screw, and an ordinary paper fastener. These articles were laid on a photographic plate and exposed for 6 days. No. 2 shows the impression of two bronze coins (halfpennies) similarly placed, - but exposed for $13 \frac{1}{2}$ days. One coin rests partly on the other, and at this part the edge of the lower coin is veri much blurred, pointing to rather great secondary nadiation from the upper coin.

Another peculiarity seems to be that while in one photographs the articles are shown as shadows, in the vomis. the coins show bright on a darker background. Does this. point to the possibility of bronze exposed to radium rays for such a period as $13 \frac{1}{2}$ days becoming more radio-active than radium itself?

Culham College, Abingdon, Berks, March I9.

NO. 1795, VOL. 69] 